Neurosurg Focus 20 (2):E1, 2006

\title{
Pediatric subaxial cervical spine injuries: origins, management, and outcome in 51 patients
}

\author{
Seref Dogan, M.D., Sam Safavi-Abbasi, M.D., Ph.D., Nicholas Theodore, M.D., \\ Eric Horn, M.D., Ph.D., Harold L. ReKaTe, M.D., and Volker K. H. Sonntag, M.D.
}

Division of Neurological Surgery and Spinal Biomechanics Laboratory, Barrow Neurological Institute, St. Joseph's Hospital and Medical Center, Phoenix, Arizona

\begin{abstract}
Object. In this study the authors evaluated the mechanisms and patterns of injury and the factors affecting management and outcome of pediatric subaxial cervical spine injuries (C3-7).

Methods. Fifty-one pediatric patients (38 boys and 13 girls; mean age 12.4 years, range 10 months-16 years) with subaxial cervical spine injuries were reviewed retrospectively. Motor vehicle accidents (MVAs) were the most common cause of injury. Overall, $12 \%$ presented with a dislocation, $63 \%$ with a fracture, $19 \%$ with a fracture-dislocation, and 6\% with a ligamentous injury. The most frequently injured level was C6-7 (33\%); C3-4 (6\%) was least frequently involved. Sixty-four percent of patients were neurologically intact, $16 \%$ had incomplete spinal cord injuries (SCIs), $14 \%$ had complete SCIs, and three patients $(6 \%)$ died after admission and before assessment. Treatment was conservative in $64 \%$ : seven $(13 \%)$ wore a halo vest and $26(51 \%)$ wore a rigid cervical orthosis. Surgery was performed in the other 18 patients (36\%), with the breakdown as follows: $15(30 \%)$ underwent an anterior approach, two (4\%) had posterior approaches, and one (2\%) had a combined approach. Postoperatively, four patients (8\%) who had a neurological deficit improved. The overall mortality rate was $8 \%$; all deaths were related to MVAs. There were no surgeryrelated deaths or complications.

Conclusions. Subaxial cervical spine injuries are common in children 9 to 16 years of age, and occur principally between $\mathrm{C}-5$ and C-7. Multilevel injury is more common in children 8 years of age and older than in younger children and infants. Most patients with subaxial cervical spine injuries can be treated conservatively. Both anterior and posterior approaches are safe and effective.
\end{abstract}

KeY WORDS • subaxial cervical spine • spinal cord injury $\bullet$ spinal fracture $\bullet$ children

$\mathrm{P}$ EDIATRIC spinal injuries constitute 1 to $10 \%$ of all cases of spinal injury. ${ }^{1,12,17,30,35}$ In this age group, 60 to $80 \%$ of all vertebral injuries involve the cervical spine, and the spinal cord is most frequently injured at the cervical level in all pediatric age groups. ${ }^{6,7,33}$ Regarding the level of injury, the upper cervical spine (above C-4) is most commonly injured in children 8 years of age and younger, whereas older children tend to be injured mainly in the lower cervical spine. ${ }^{17}$ In our two previously reported large series of pediatric cervical injuries, ${ }^{13,17} 69$ to $78 \%$ of the patients 9 years of age and younger sustained upper cervical injuries (occiput-C2), whereas 70 to $73 \%$ of the patients 10 years of age and older sustained lower cervical spine injuries $(\mathrm{C} 3-7)$.

We reviewed our experience in the last 6.5 years with subaxial pediatric spinal injuries, defined as injuries involving the levels between C-3 and C-7, to determine

Abbreviations used in this paper: $\mathrm{CT}=$ computerized tomography; $\mathrm{MR}=$ magnetic resonance; $\mathrm{MVA}=$ motor vehicle accident; $\mathrm{SCI}=$ spinal cord injury; $\mathrm{VB}=$ vertebral body. mechanisms and patterns of injury and factors affecting management and outcome.

\section{Clinical Material and Methods}

All pediatric trauma admissions to our Level I trauma service since 1999 were reviewed retrospectively. All patients 16 years of age and younger who presented with cervical spine trauma were included in the study. Between 1999 and June 2005, 51 pediatric patients (38 boys and 13 girls; mean age 12.4 years, range 10 months-16 years) with subaxial cervical spine injuries with and without SCIs were treated. Forty-one patients with a subaxial spine injury (80\%) were between 9 and 16 years of age, and $10(20 \%)$ were between 0 and 9 years of age.

The predominant mechanism of subaxial cervical spine injury (Table 1) was an MVA (50\%), followed by sportsrelated activities (25\%), fall-related injuries $(17 \%)$, motor vehicle versus pedestrian accidents $(6 \%)$, and motorcycle accidents (2\%). Of the cases involving MVAs, $52 \%$ of patients were unrestrained at the time of the accident (13 cases). Patients with missile, brachial plexus, or peripheral nerve injuries were excluded from the study. 
S. Dogan, et al.

Diagnostic radiographic studies, including plain cervical x-ray films (anteroposterior, lateral, and swimmer's views) and CT scans were obtained in all patients. Flexion-extension radiographs were obtained to assess spinal stability in awake and neurologically intact patients. If the presence of a fracture was uncertain or if a patient had an SCI, MR imaging was performed (32 cases, 63\%).

We evaluated the level and pattern of injury, the diagnosis made, the incidence of neurological compromise, associated injuries, radiographic findings, and outcomes. The patients' neurological function was graded according to the Frankel classification. ${ }^{15}$ Follow-up assessment included clinical evaluation and 3- and 6-month radiographic studies (mean follow-up duration 9.05 months, range 2.5-53 months).

\section{Results}

\section{Patterns of Injury}

Four patterns of injury were recognized on radiographic studies: fractures (63\%), fracture with dislocation (19\%), dislocation $(12 \%)$, and purely ligamentous injury $(6 \%)$. Single-level injuries were distributed along the cervical spine as follows: three $(6 \%)$ at $\mathrm{C} 3-4 ; 10(20 \%)$ at C4-5; $12(23 \%)$ at $\mathrm{C} 5-6$; and $17(33 \%)$ at C6-7 (Table 2). In nine children $(18 \%)$ the injury involved more than one level.

Of the 51 patients, $33(64 \%)$ were neurologically intact on admission, eight (16\%) had incomplete neurological injuries, and seven (14\%) had a complete SCI. Neurological status (according to Frankel grade) could not be evaluated in three patients with severe head injury. Associated injuries included head/facial trauma (24\%), multiple trauma (10\%), and orthopedic injuries (6\%).

\section{Treatment of Injuries}

Axial traction was applied in 25 patients as soon as possible after admission. Realignment of a kyphotic deformity and reduction of dislocated facet joints were attempted, and careful neurological monitoring and radiological evaluation of the reduction were performed. All patients with neurological deficits and compressive injuries underwent immediate surgery.

Of the 51 children, 18 (36\%) required surgical intervention (Table 3). An anterior cervical approach was performed in 15 patients $(83 \%)$. Of these, three $(20 \%)$ had VB fractures, seven $(47 \%)$ had a fracture and dislocation, four (26\%) had vertebral dislocations, and one (7\%) had a ligamentous injury. In 11 surgical cases $(61 \%)$, anterior cervical discectomy and fusion was the only procedure performed. Four patients (22\%) were treated with corpectomy, allograft bone, and plate fixation (Fig. 1). The posterior approach was performed in two patients (11\%) (Fig. 2). One patient $(6 \%)$ with a C-7 fracture-dislocation underwent a combined anterior-posterior approach. The age range of surgically treated patients was 8 to 16 years (Table 4). Injuries in the younger patient population in our series did not require surgical intervention. All patients wore either a Miami J or a Philadelphia collar for 8 to 12 weeks postsurgery.

Thirty-three patients were treated nonsurgically. Seven
TABLE 1

Mechanism of injury in pediatric subaxial spine injuries

\begin{tabular}{lc}
\hline \hline \multicolumn{1}{c}{ Mechanism of Injury } & No. of Patients (\%) \\
\hline MVA & \\
unrestrained & $13(25)$ \\
restrained & $12(24)$ \\
sports & $13(25)$ \\
fall & $9(17)$ \\
automobile vs pedestrian accident & $3(6)$ \\
motorcycle accident & $1(2)$ \\
\hline
\end{tabular}

of them wore a halo vest or other rigid cervicothoracic stabilizing device, and 26 wore a rigid cervical orthosis for a mean of 8 to 12 weeks. In a 10-month-old infant with unilateral facet dislocation, two attempts at fluoroscopically guided closed reduction were unsuccessful and the patient was placed in a specially designed external orthosis. All patients underwent follow-up evaluation with CT scanning or dynamic flexion-extension x-ray films. None of the conservatively treated patients needed surgical intervention in the follow-up period for nonfusion or instability, or for complications.

\section{Postoperative Outcomes}

Solid arthrodesis was demonstrated in all 15 patients who underwent fusion procedures and were available for followup evaluation (mean duration 13.43 months, range 2.5-40 months). Of the conservatively treated patients, 24 were available for follow up, six were lost to follow up, and three died. There were no surgery-related deaths or complications. The neurological condition of all 33 patients who

TABLE 2

Summary of clinical data in 51 pediatric patients with subaxial cervical injuries at admission*

\begin{tabular}{cc}
\hline \multicolumn{1}{c}{ Factor } & No. of Patients (\%) \\
\hline level of injury & \\
C3-4 & $3(6)$ \\
C4-5 & $10(20)$ \\
C5-6 & $12(23)$ \\
C6-7 & $17(33)$ \\
multilevel & $9(18)$ \\
fx & $1(2)$ \\
burst & $10(20)$ \\
compression & $6(12)$ \\
teardrop & $15(29)$ \\
pst element & $5(10)$ \\
disloc & $1(2)$ \\
unilat & $10(19)$ \\
bilat & $3(6)$ \\
fx \& disloc & \\
lig injury & $7(14)$ \\
neuro status at admission & $8(16)$ \\
complete & $33(65)$ \\
incomplete & $3(6)$ \\
intact &
\end{tabular}

$*$ Disloc = dislocation; $\mathrm{fx}=$ fracture; lig = ligament $\mathrm{ND}=$ not determined; neuro $=$ neurological; pst $=$ posterior .

$\dagger$ Comatose on admission; neurological evaluation could not be performed. 
TABLE 3

Clinical summary of management and outcome in 51 patients with subaxial cervical injury

\begin{tabular}{cc}
\hline \multicolumn{1}{c}{ Factor } & No. of Patients $(\%)$ \\
\hline surgical tx & \\
ant discect \& fusion* & $11(22)$ \\
corpectomy/fusion & $4(8)$ \\
pst fusion & $2(4)$ \\
combined & $1(2)$ \\
nonsurgical tx & \\
rigid orthosis & $26(51)$ \\
halo vest & $7(13)$ \\
outcome & \\
complete & $4(8)$ \\
incomplete & $6(12)$ \\
intact & $37(72)$ \\
death & $4(8)$
\end{tabular}

* Ant = anterior; discect $=$ discectomy; $\mathrm{tx}=$ treatment.

were intact on admission and available for follow-up review remained stable. Of the eight patients with an incomplete neurological deficit on admission who were available for follow up, five improved one neurological grade and were intact at their last examination, whereas three remained unchanged. Of the seven patients with complete neurological deficits, one died after admission, and the other six were available for follow up. Of these, one improved from Frankel Grade A to C, another improved from Grade A to D, and four remained unchanged.

Ten patients with complete or incomplete injuries were transferred to a rehabilitation center. The mean duration of hospital stay was 7 days (range 1-78 days). Long hospital stays reflected concomitant injuries or severe neurological deficits. One patient with a complete SCI died within 12 hours of head injury. Three other patients also died of a concomitant severe head injury.

\section{Discussion}

\section{Patterns and Mechanisms of Subaxial Cervical Spine Injury}

Several factors contribute to differences in the frequency, type, location, and incidence of spinal column and cord injuries in children compared with those in adults. These differences are largely attributed to developmental, anatomical, and biomechanical factors associated with the pediatric spine. ${ }^{35}$ The disproportionately large head and underdeveloped neck musculature in the pediatric population contribute to greater bending of the cervical spine when it is subjected to flexion and extension forces. Furthermore, the elasticity of the joint capsules, ligaments, and cartilaginous endplates serves to absorb and distribute traumatic forces. Horizontally angulated articulating facets, especially at C1-2, and wedge-shaped VBs allow anterior sliding. 3,10,17,18,36 The resulting patterns of injury include cervical fractures and dislocation (especially in the upper cervical spine), SCI without radiographic abnormality, and severe ligamentous injury. ${ }^{11,18,31}$

A child's cervical spine does not attain the characteristics of the adult spine until the individual is 8 or 9 years old. Thereafter, the vertebrae usually start to ossify and mature, the VB loses its wedge shape, the facets become more vertically aligned, the cervical musculature becomes more developed, and the ligaments and capsules gain more tensile strength. ${ }^{14,17,21,33}$

Young children seem to sustain upper cervical injuries, whereas adolescents tend to sustain lower cervical injuries. As demonstrated in our findings, most of the patients with subaxial injuries $(60 \%)$ were between 9 and 16 years of age. This pattern reflects the fulcrum of cervical motion at C5-6 in adolescents, whereas it is located at C2-3 in younger children. ${ }^{18,28}$ In our patients, the most commonly involved levels in subaxial injury were C6-7 and C5-6 (33 and 23\%, respectively), which is consistent with the recent literature. Kokoska, et al., ${ }^{22}$ reported that $56 \%$ of their patients sustained injuries between C-5 and C-7, and
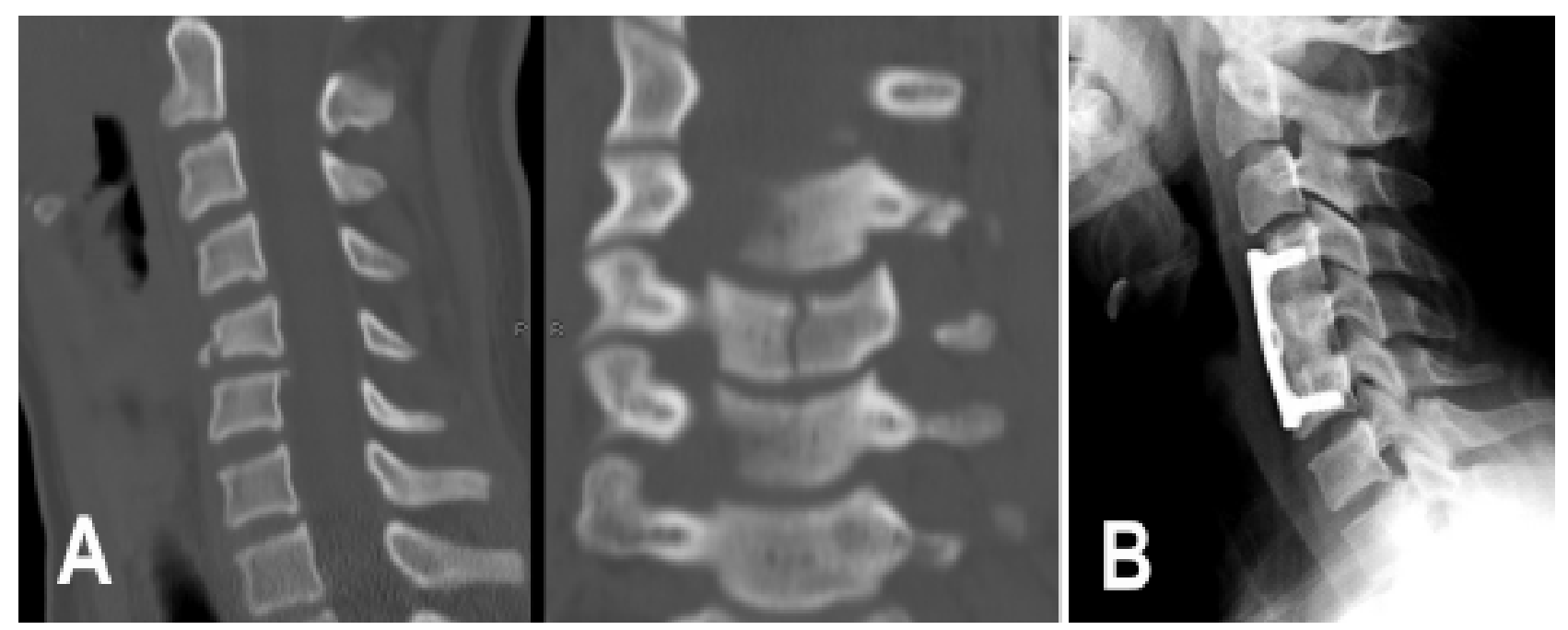

FIG. 1. A: Reconstructed sagittal (left) and coronal (right) CT scans obtained in a 10-year-old patient with a C-6 fracture and kyphosis. B: Lateral radiograph obtained 1 year after surgical stabilization, confirming excellent alignment and fusion. 
S. Dogan, et al.
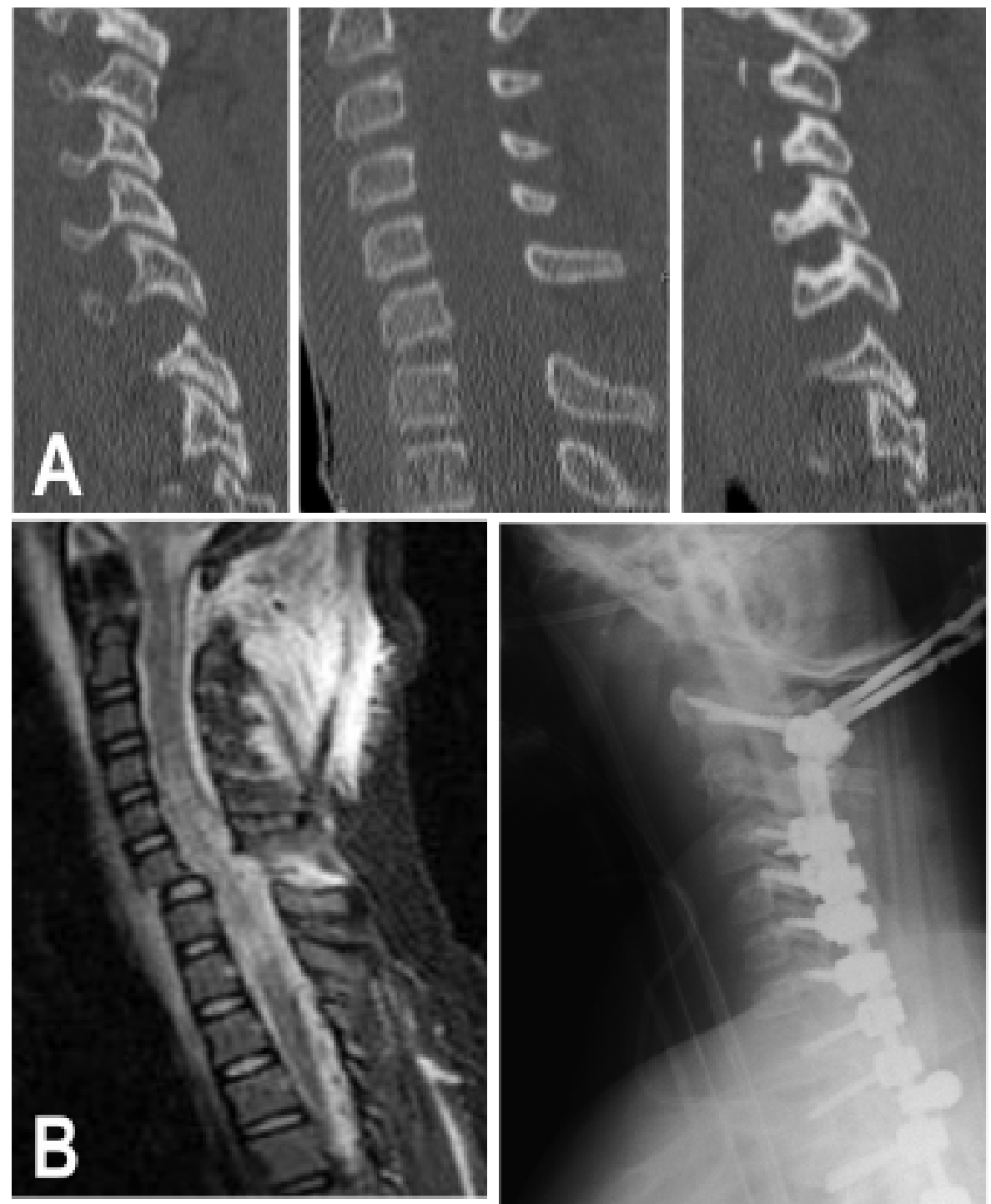

FIG. 2. A: Reconstructed sagittal CT scans obtained in an 8year-old boy, demonstrating C6-7 subluxation and widening of the facets at that level. This patient also had a craniocervical injury. B: Sagittal $\mathrm{T}_{2}$-weighted $\mathrm{MR}$ image demonstrating the

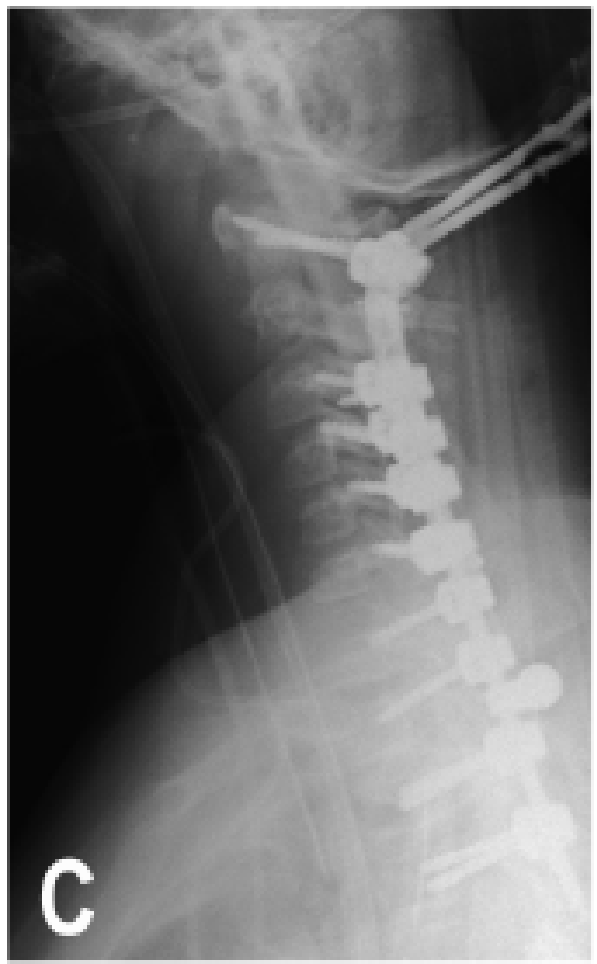
severe SCI at C6-7. C: Postoperative plain X-ray film showing the posterior occipital-to-thoracic (T-3) instrumentation needed to stabilize the patient's multilevel cervical injuries.

Patel, et al., ${ }^{32}$ found that $28 \%$ of their patients had injuries between these levels.

Nine $(18 \%)$ of our patients had injuries involving more than one segment of the spine. In fact, the incidence of multilevel spinal involvement reported in the literature ranges from 7 to $22 \%$ in children. 5,37 This high incidence is attributed to the increased flexibility of the immature spine, ${ }^{3,36}$ although all of our patients with multilevel injuries were 8 years of age and older. Nevertheless, flexibility of the spine may not be the only explanation. Even older children with stiffer spines or adults may have a similar incidence of multilevel involvement. In adults, the incidence of multilevel cervical spine injury is reported to be approximately $19 \% .{ }^{19}$ The dissipation of the energy of a trauma-producing force through a smaller body, or the amount of that force may explain the high incidence of multilevel involvement. ${ }^{6}$ Interestingly, all patients in the surgically treated group were 8 years and older (Table 4), whereas the injuries in younger patients could be managed conservatively.

At our institution, spinal injuries included minor ones such as spinous process fractures, as well as severe fracture-dislocations of the spine. Most of our patients had fractures involving the posterior elements (spinous process, lamina, facet, and pedicle fracture). Compression fractures and fracture-dislocations occurred at equal rates $(19 \%)$. Patients with a dislocation or fracture-dislocation had a higher incidence of neurological injury than patients with a fracture alone. This finding is to be expected because dislocation and fracture-dislocation cause a greater 
TABLE 4

Summary of 18 pediatric patients who underwent surgical treatment for subaxial spinal injuries*

\begin{tabular}{|c|c|c|c|c|c|c|}
\hline $\begin{array}{l}\text { Case } \\
\text { No. }\end{array}$ & $\begin{array}{l}\text { Age (yrs), } \\
\text { Sex }\end{array}$ & Level of Injury & $\begin{array}{l}\text { Preop Neuro Status } \\
\text { (Frankel grade) }\end{array}$ & Procedure & $\begin{array}{l}\text { Postop Neuro Status } \\
\text { (Frankel grade) }\end{array}$ & $\mathrm{FU}$ \\
\hline 1 & $8, \mathrm{M}$ & C6-7 fx, C1-2 disloc & complete $(\mathrm{A})$ & Oc-T3 pst stabilization & incomplete $(\mathrm{C})$ & $10 \operatorname{mos}$ \\
\hline 2 & $8, \mathrm{M}$ & $\begin{array}{l}\text { C6-7 fx \& disloc, } \\
\text { C1-4 pst element fx }\end{array}$ & complete (A) & Oc-T1 pst stabilization & died & 12 days postadmission \\
\hline 3 & $8, \mathrm{~F}$ & C6-7 fx \& disloc & incomplete (B) & ant fusion, C6-7 stabilization & incomplete (B) & lost to FU \\
\hline 4 & $10, \mathrm{~F}$ & C5-6 fx \& disloc & intact $(\mathrm{E})$ & C-5 corpectomy, fusion, C4-6 stabilization & intact $(\mathrm{E})$ & $13 \operatorname{mos}$ \\
\hline 5 & $12, \mathrm{M}$ & C6-7 fx \& disloc & intact $(\mathrm{E})$ & ant fusion, C6-T1 stabilization & intact $(\mathrm{E})$ & lost to FU \\
\hline 6 & $13, \mathrm{~F}$ & C5-6 unilat disloc & incomplete (D) & ant fusion, C5-6 stabilization & intact $(\mathrm{E})$ & $12 \operatorname{mos}$ \\
\hline 7 & $13, \mathrm{M}$ & C-4 compression $\mathrm{fx}$ & intact $(\mathrm{E})$ & C-4 corpectomy, fusion, C3-5 stabilization & intact $(\mathrm{E})$ & $9 \operatorname{mos}$ \\
\hline 8 & $13, \mathrm{M}$ & C6-7 bilat disloc & incomplete (D) & ant fusion, C6-7 stabilization & incomplete (D) & $8 \mathrm{mos}$ \\
\hline 9 & $14, \mathrm{M}$ & C5-6 unilat disloc & incomplete (D) & ant fusion, C5-6 stabilization & intact $(\mathrm{E})$ & $13 \operatorname{mos}$ \\
\hline 10 & $15, \mathrm{M}$ & C4-5 fx \& disloc & complete $(\mathrm{A})$ & C-5 corpectomy, fusion, C4-6 stabilization & complete $(\mathrm{A})$ & $2.5 \mathrm{mos}$ \\
\hline 11 & $15, \mathrm{M}$ & C3-4, C4-5 fx \& disloc & incomplete (B) & ant fusion, C3-5 stabilization & incomplete (B) & $40 \mathrm{mos}$ \\
\hline 12 & $15, \mathrm{~F}$ & C6-7 fx \& disloc & complete $(\mathrm{A})$ & $\begin{array}{l}\text { C-7 corpectomy, fusion, C6-T1 stabilization } \\
\text { \& pst wiring C6-T1 }\end{array}$ & complete $(\mathrm{A})$ & $12 \operatorname{mos}$ \\
\hline 13 & $15, \mathrm{M}$ & C-6 compression $\mathrm{fx}$ & complete (A) & C6 corpectomy, fusion, $\mathrm{C} 5-7$ stabilization & complete (A) & $9 \operatorname{mos}$ \\
\hline 14 & $15, \mathrm{M}$ & C6-7 fx \& disloc & intact $(\mathrm{E})$ & ant fusion, $\mathrm{C} 6-7$ stabilization & intact $(\mathrm{E})$ & $13 \operatorname{mos}$ \\
\hline 15 & $15, \mathrm{M}$ & C4-5 lig injury & incomplete (D) & ant fusion, C4-5 stabilization & intact $(\mathrm{E})$ & $24 \operatorname{mos}$ \\
\hline 16 & $15, \mathrm{M}$ & C4-5 unilat disloc & complete (A) & ant fusion, C4-5 stabilization & incomplete (D) & $7 \operatorname{mos}$ \\
\hline 17 & $16, \mathrm{M}$ & C- 6 burst fx & complete (A) & ant fusion, C6-7 stabilization & complete (A) & $9 \operatorname{mos}$ \\
\hline 18 & $16, \mathrm{M}$ & C4-5 fx \& disloc & incomplete $(\mathrm{C})$ & ant fusion, C4-5 stabilization & incomplete $(\mathrm{C})$ & $8 \mathrm{mos}$ \\
\hline
\end{tabular}

$* \mathrm{FU}=$ follow up; Oc = occiput.

degree of displacement, and more force is usually required to produce such displacement.

The most common mechanisms of subaxial injury were MVAs (50\%) and sports-related accidents $(25 \%)$. This is similar to our overall experience with pediatric cervical spine injury: $48 \%$ were caused by MVAs and $35 \%$ were sports-related accidents in our earlier studies. 13,17 In the series reported by Patel, et al., ${ }^{32}$ MVAs caused $61 \%$ of the injuries and $18 \%$ involved falls. Thus, the mechanisms of subaxial cervical spine injury do not differ overall from the mechanisms responsible for injury to the entire cervical spine. Alarmingly, however, more than half of our patients involved in MVAs (52\%) were unrestrained.

As many as $66 \%$ of the cervical spine injuries encountered in pediatric patients may be associated with head injury. ${ }^{2,26}$ In our current series, this rate was lower (24\%) than the findings in our previous report $(40 \%) .{ }^{13}$ It is also lower than the findings in other studies, which have ranged from 30 to $53 \% .^{16,29}$ These findings are plausible and are consistent with our previous report, considering that mainly patients with upper cervical injuries had associated head trauma. ${ }^{13}$

\section{Management of Pediatric Subaxial Cervical Injuries}

Treatment of such injuries during a period of growth may be problematic. Most of these injuries can be treated nonsurgically with external stabilization. ${ }^{14,24,30}$ Nevertheless, the management of cervical spine injuries in the pediatric population must be individualized. Therapy depends on the patient's age, severity and level of injury, amount of neurological compromise, and the presence of associated injuries. ${ }^{34}$

Any patient with a suspected spine injury must be immobilized until the entire vertebral column and spinal cord have been assessed and cleared. As observed in our study, as many as $18 \%$ of patients may be injured at more than one level. Thus, full spinal column assessment is indicat- ed for these patients, as it is for patients with severe head or systemic trauma, or those who are unconscious.

Radiological evaluation begins with routine plain x-ray films. The standard trauma series for cervical spine clearance includes anteroposterior, lateral, and open-mouth radiographs of the cervical spine, which must include the cervicothoracic junction. Fractures identified on plain xray films and nonvisualized regions are delineated further by thin-section CT scans. Patients with neurological deficits should undergo MR imaging to exclude the presence of an acute lesion, such as an extradural hematoma or herniated disc. ${ }^{8,30}$ Follow-up radiological assessment may be performed using dynamic flexion-extension radiographs or CT scans. In our series we preferred dynamic radiographs for evaluation of solid fusion.

After initial immobilization and, if possible, reduction, emergency surgical intervention is seldom required; most injuries can be managed nonsurgically. In our study, 33 patients $(64 \%)$ were treated conservatively. In six patients (including a 10-month-old infant) the injuries were managed successfully with a halo vest or a specially designed external orthosis, with no complications. One patient who was placed in a halo vest died of traumatic head injury within 12 hours. Mubarak, et al., ${ }^{27}$ described halo application to immobilize three infants who were 7,16 , and 24 months of age. The patients were maintained in the halo devices for 2 to 3.5 months. Marks, et al., ${ }^{23}$ described the treatment of eight children between 3 months and 12 years of age who were immobilized in halo vests for 6 weeks to 12 months. Osenbach and Menezes ${ }^{30}$ found that halo vest therapy provided superior immobilization, and they recommended its use for treatment of the cervical spine in children. Previously, we successfully treated 42 patients with cervical spine injury by placing them in a halo vest; ${ }^{17}$ however, the use of a halo vest requires special consideration and diligent follow-up evaluation to avoid complications. 
S. Dogan, et al.

Indications for surgical intervention include failure to achieve reduction, persistent instability, ligamentous injury with facet instability, a greater than $15^{\circ}$ spinal kyphotic deformity, significant VB compression fracture, vertebral dislocation, and spinal cord compression associated with progressive neurological symptoms.$^{20}$ Extradural hematomas and herniated discs are also indications for acute surgical intervention, particularly in patients with incomplete injuries. ${ }^{30}$

Successful arthrodesis and solid fusion associated with good alignment and normal growth of the cervical spine during the follow-up period has been associated with both anterior and posterior approaches., ${ }^{4,17,25,36}$ In this series, 15 patients $(30 \%)$ with a subaxial cervical injury underwent an anterior approach, two were treated with a posterior approach, and one underwent a combined anterior-posterior approach. In all cases solid fusion was achieved. There was evidence of good alignment and cervical growth at follow up. No postoperative instability and no significant postfusion spinal deformity were observed in any of the patients after rigid screw fixation.

\section{Outcome of Pediatric Subaxial Cervical Injuries}

The prognosis of pediatric cervical spine injury depends on the presence of neurological injury at presentation. In our series, all neurologically intact patients remained so at follow-up evaluations. Of the patients with incomplete injuries, $62.5 \%$ recovered completely. The high capacity for recovery in these young patients is thought to be related to the rapid healing properties of bone and ligaments in children as well as to the greater potential for recovery of the nervous system., ${ }^{9}, 17$ Of the six patients with complete neurological deficits who were available for follow up, one improved three Frankel grades and another improved two grades, whereas four patients remained unchanged. Nevertheless, patients with complete injuries may recover relatively late after injury. ${ }^{9,17}$

The lower mortality rate $(8 \%)$ observed in this series compared with the overall reported mortality rate (16$35 \%$ ) for pediatric cervical injury may reflect our focus on subaxial cervical injuries. Upper cervical injuries are associated with a higher rate of head injuries and seem to be associated with poor outcomes.

\section{Conclusions}

Subaxial cervical spine injuries are most common in children between 9 and 16 years of age and are principally located between the C-5 and C-7 vertebrae. Multilevel injuries are most common in children 8 years of age and older, and are rare in younger children and infants. The treatment in each patient must be individualized. Most patients with subaxial cervical spine injuries can be treated conservatively. When indicated, both anterior and posterior approaches are safe and effective for the treatment of pediatric subaxial cervical spine injuries. Complications are minimal and the rate of bone fusion is high. Surgery also allows immediate postoperative mobilization of patients. The prognosis for neurological recovery from pediatric subaxial cervical spine injuries is related to the initial severity of the neurological injuries, but may be better than in the adult population.

\section{References}

1. Akbarnia BA: Pediatric spine fractures. Orthop Clin North Am 30:521-536, 1999

2. Birney TJ, Hanley EN Jr: Traumatic cervical spine injuries in childhood and adolescence. Spine 14:1277-1282, 1989

3. Bohn D, Armstrong D, Becker L, et al: Cervical spine injuries in children. J Trauma 30:463-469, 1990

4. Brockmeyer D, Apfelbaum R, Tippets R, et al: Pediatric cervical spine instrumentation using screw fixation. Pediatr Neurosurg 22:147-157, 1995

5. Brown RL, Brunn MA, Garcia VF: Cervical spine injuries in children: a review of 103 patients treated consecutively at a level 1 pediatric trauma center. J Pediatr Surg 36:1107-1114, 2001

6. Carreon LY, Glassman SD, Campbell MJ: Pediatric spine fractures: a review of 137 hospital admissions. J Spinal Disord Tech 17:477-482, 2004

7. Cirak B, Ziegfeld S, Knight VM, et al: Spinal injuries in children. J Pediatr Surg 39:607-612, 2004

8. d'Amato C: Pediatric spinal trauma: injuries in very young children. Clin Orthop Relat Res 432:34-40, 2005

9. Davis L: Treatment of spinal cord injuries. AMA Arch Surg 69:488-495, 1954

10. Dickman CA, Rekate H: Spinal trauma, in Eichelberger MR (ed): Pediatric trauma: prevention, acute care, rehabilitation. St. Louis: Mosby-Year Book, 1993, pp 362-377

11. Dickman CA, Rekate HL, Sonntag VK, et al: Pediatric spinal trauma: vertebral column and spinal cord injuries in children. Pediatr Neurosci 15:237-256, 1989

12. Dickman CA, Zabramski JM, Hadley MN, et al: Pediatric spinal cord injury without radiographic abnormalities: report of 26 cases and review of the literature. J Spinal Disord 4:296-305, 1991

13. Eleraky MA, Theodore N, Adams M, et al: Pediatric cervical spine injuries: report of 102 cases and review of the literature. J Neurosurg (1 Suppl) 92:12-17, 2000

14. Fesmire FM, Luten RC: The pediatric cervical spine: developmental anatomy and clinical aspects. J Emerg Med 7: 133-142, 1989

15. Frankel HL, Hancock DO, Hyslop G, et al: The value of postural reduction in the initial management of closed injuries of the spine with paraplegia and tetraplegia. I. Paraplegia 7: 179-192, 1969

16. Givens TG, Polley KA, Smith GF, et al: Pediatric cervical spine injury: a three-year experience. J Trauma 41:310-314, 1996

17. Hadley MN, Zabramski JM, Browner CM, et al: Pediatric spinal trauma. Review of 122 cases of spinal cord and vertebral column injuries. J Neurosurg 68:18-24, 1988

18. Hill SA, Miller CA, Kosnik EJ, et al: Pediatric neck injuries. A clinical study. J Neurosurg 60:700-706, 1984

19. Iencean SM: Double noncontiguous cervical spinal injuries. Acta Neurochir (Wien) 144:695-701, 2002

20. Joint Section on Disorders of the Spine and Peripheral Nerves of the AANS/CNS: Treatment of subaxial cervical spinal injuries. Neurosurgery 50:S156-S165, 2002

21. Kewalramani LS, Tori JA: Spinal cord trauma in children. Neurologic patterns, radiologic features, and pathomechanics of injury. Spine 5:11-18, 1980

22. Kokoska ER, Keller MS, Rallo MC, et al: Characteristics of pediatric cervical spine injuries. J Pediatr Surg 36:100-105, 2001

23. Marks DS, Roberts P, Wilton PJ, et al: A halo jacket for stabilisation of the paediatric cervical spine. Arch Orthop Trauma Surg 112:134-135, 1993

24. McGrory BJ, Klassen RA: Arthrodesis of the cervical spine for fractures and dislocations in children and adolescents. A longterm follow-up study. J Bone Joint Surg Am 76:1606-1616, 1994 


\section{Pediatric subaxial cervical spine injury}

25. McWhorter JM, Alexander E, Davis $\mathrm{CH}$, et al: Posterior cervical fusion in chidren. J Neurosurg 45:211-215, 1976

26. Michael DB, Guyot DR, Darmody WR: Coincidence of head and cervical spine injury. J Neurotrauma 6:177-189, 1989

27. Mubarak SJ, Camp JF, Vuletich W, et al: Halo application in the infant. J Pediatr Orthop 9:612-614, 1989

28. Nitecki S, Moir CR: Predictive factors of the outcome of traumatic cervical spine fracture in children. J Pediatr Surg 29: 1409-1411, 1994

29. Orenstein JB, Klein BL, Gotschall CS, et al: Age and outcome in pediatric cervical spine injury: 11-year experience. Pediatr Emerg Care 10:132-137, 1994

30. Osenbach RK, Menezes AH: Pediatric spinal cord and vertebral column injury. Neurosurgery 30:385-390, 1992

31. Pang D, Wilberger JE Jr: Spinal cord injury without radiographic abnormalities in children. J Neurosurg 57:114-129, 1982

32. Patel JC, Tepas JJ III, Mollitt DL, et al: Pediatric cervical spine injuries: defining the disease. J Pediatr Surg 36:373-376, 2001

33. Rahimi SY, Stevens EA, Yeh DJ, et al: Treatment of atlantoaxial instability in pediatric patients. Neurosurg Focus 15:ECP1, 2003

34. Rauzzino MJ, Hadley MN: Pediatric spinal cord injuries, in Me- nezes AH, Sonntag VK (eds): Principles of Spinal Surgery. New York: McGraw-Hill, 1996, pp 817-840

35. Rekate HL, Theodore N, Sonntag VK, et al: Pediatric spine and spinal cord trauma. State of the art for the third millennium. Childs Nerv Syst 15:743-750, 1999

36. Ruge JR, Sinson GP, McLone DG, et al: Pediatric spinal injury: the very young. J Neurosurg 68:25-30, 1988

37. Zuckerbraun BS, Morrison K, Gaines B, et al: Effect of age on cervical spine injuries in children after motor vehicle collisions: effectiveness of restraint devices. J Pediatr Surg 39:483-486, 2004

Manuscript received December 15, 2005.

Accepted in final form January 11, 2005.

Address for Dr. Dogan: Uludag University Faculty of Medicine, Department of Neurosurgery, Bursa, Turkey.

Address reprint requests to: Nicholas Theodore, M.D., c/o Neuroscience Publications, Barrow Neurological Institute, 350 West Thomas Road, Phoenix, Arizona 85013. email: neuropub@chw.edu. 